\title{
ИЗУЧЕНИЕ КОЛЛЕКТИВНОГО ВОЗМЕЩЕНИЯ В ОТНОШЕНИИ ПРАВА СОЛИДАРНОСТИ
}

\section{ОРИГИНАЛЬНАЯ СТАТЬЯ}

RIBEIRO, Danilo Miranda ${ }^{1}$

RIBEIRO, Danilo Miranda. Изучение коллективного возмещения в отношении права солидарности. Revista Científica Multidisciplinar Núcleo do Conhecimento. Год. 06, Изготовить. 12, Vol. 02, с. 152-167. Декабрь 2021 года. ISSN: 2448-0959, Ссылка доступа: https://www.nucleodoconhecimento.com.br/закон/правасолидарности, DOI: 10.32749/nucleodoconhecimento.com.br/ru/103914

\section{СВОДКА}

Эта работа направлена на построение юридического анализа элементов коллективного процесса защиты права солидарности в бразильской правовой системе. Из-за того, что его положения в законах разнесены, изучение коллективной опеки сталкивается с проблемой герметичной системы, которую трудно понять. Стремясь открыть путь к изучению коллективного процесса и устранить эту проблему, настоящее исследование имеет своей проблематикой обсуждение основных элементов коллективного процесса, стремясь продемонстрировать, что это последовательная и гармоничная процедурная система. Используемая методология представляет собой обзор литературы. Таким образом, работа представляет собой систематизацию пунктов, которые имеют фундаментальное значение для понимания коллективной опеки, путем рассмотрения правовых и доктринальных положений о защите права солидарности, чтобы открыть поле для понимания коллективной опеки.

Ключевые слова: коллективный процесс, права солидарности, гражданский процесс, принципы.

\footnotetext{
${ }^{1}$ Степень магистра в области прав человека и демократии в UFPR - Федеральный университет Парана. Бакалавр права, UCSal-Католический университет Сальвадор. ORCID: https://orcid.org/0000-0001-65039625.

RC: 103914

Доступно в: https://www.nucleodoconhecimento.com.br/закон/права-солидарности
} 


\section{1. ВВЕДЕНИЕ}

Коллективная защита является важным процессуальным инструментом для реализации социальной справедливости путем защиты правовых активов, которые принадлежат не только отдельному лицу, но и касаются коллектива. Получается, что правовые положения об институте содержатся в различных законодательных актах и не обходятся без конституционного понимания вопроса, что может стать препятствием для последовательного расследования коллективного процесса. С учетом этой проблемы данное исследование призвано предложить размышление о важнейших элементах коллективной защиты права солидарности, таких, как концепция права солидарности, легитимность и компетенция. Таким образом, коллективный процесс будет представлен в согласованном и гармоничном ключе с руководящими конституционными принципами, с тем чтобы устранить герметизм, который может быть воспринят путем знания коллективной защиты. Использованной методологией будет библиографический обзор авторов, внесших важный вклад в понимание охраны права солидарности.

С конституционной точки зрения, принцип надлежащей правовой процедуры (статья 5, LIV, CF / 88) должен толковаться в его коллективном аспекте, поскольку он направлен на сокращение фрормальностей для обеспечения эфффективного и справедливого метаиндивидуального процесса. к юрисдикции. Коллективная процессуальная система придает легитимность разным субъектам (ope legis), поскольку актуальность защищаемых интересов вызывает ответственность разных субъектов за обеспечение прав коллектива. В этом смысле искусство. 103, CDC помещает эффеективность erga omnes или ultra partes для решений, принимаемых в коллективном процессе (BELLINETTI; SOUZA, 2019).

Что касается классификации, то Zavascki (2005, стр. 18) делит интересы коллективно на две категории. Первыми были бы однородные индивидуальные интересы, которые имели бы свой коллективный характер для эмпирического, 
случайного, ненужного вопроса, в котором было бы несколько субъектов, но объект делим. Вторая категория будет охватывать диффузные и коллективные интересы, состоящие из тех, которые являются коллективными по своей сути, которые касаются неделимого объекта и неопределенного числа субъектов. Применительно к солидарности интересам их можно рассматривать в двух отдельных областях: однородные индивидуальные права и stricto sensu и дифрфузные коллективные права.

По мнению Ronaldo Santos (2014), идея защиты права коллектива заключается в обеспечении социальной справедливости обиженных социальных групп или в судебном урегулировании ситуаций, которые ранее не имели судебной защиты. Для автора коллективные действия были предшественником Bill of Peace, который восходит к истории семнадцатого века:

[...] tratava de uma autorização para o processamento de uma ação individual sob a forma coletiva, concedida nas hipóteses em que o autor requeria que o provimento da demanda englobasse os direitos de todos os indivíduos que estivessem em igual condição de litígio, para que a questão fosse tratada de modo uniforme e com vistas a evitar a multiplicação de processos (SANTOS, 2014, p. 238).

Делая акцент на взаимосвязи права солидарности как основных прав, Хашем понимает, что первые несут те же элементы, которые были бы связаны с основными правами трех поколений, а не только третьего, второго или первого поколения:

Por conta da complexidade de sua natureza jurídica e estrutura normativa, todos os direitos fundamentais reúnem concomitantemente a totalidade dos traços que supostamente seriam peculiares a cada uma das gerações: (i) impõem deveres negativos ao Estado; (ii) dirigem ao Poder Público obrigações de fornecer prestações fáticas e normativas; (iii) ostentam a titularidade transindividual alegadamente exclusiva dos "direitos de terceira geração", bem como, simultaneamente, a titularidade individual pretensamente típica dos "direitos de primeira e segunda geração" (HACHEM, 2013, p. 621).

Благодаря коллективным требованиям увеличивается доступ к правосудию неопределенной общности или определенной группы людей. Преимущества 
этих действий заключаются в социализации и демократизации процесса с реализацией прав и изменением социальной реальности; возможность исправления правонарушения, которое не было бы постулировать в индивидуальном требовании, учитывая его крошечную особую ценность, но которое в совокупности имеет большое социальное воздействие; равенство между сторонами в судебном процессе; молекуляризация требований и реализация принципа правовой определенности и законного доверия перед единообразными решениями по аналогичным делам; снижение требований к судебной системе, среди прочего.

Более конкретно, однородные индивидуальные интересы носят одежду индивидуальных интересов, но перед лицом определенных конфигураций общества существует необходимость коллективной защиты. Сама номенклатура уже переводит часть концепции этого интереса, согласно уроку Zavascki:

$\mathrm{Na}$ verdade, a própria denominação interesses individuais homogêneos já exibe dois enunciados: de um lado, trata-se de interesses ontologicamente individuais, não coletivos; de outro lado, que consistem numa multiplicidade de interesses individuais apresentando um determinado grau de uniformidade ou homogeneidade, sua característica mais importante (ZAVASCKI, 2005, p. 18).

Согласно статье 81 Закона 8.078/91, однородные индивидуальные интересы основаны на идее общего происхождения, на вредном фракте, который затрагивает и нарушает бесчисленное количество людей в их индивидуальности, без требования основных правовых отношений между держателями или между сторонами, а также единицы в отношении факта или временности (ZAVASCKI, 2005, стр. 21).

Однородные индивидуальные интересы - это те, которые имеют в своем происхождении вредный фракт, который повлиял на коллектив и преодолел сферу индивидуальных интересов. Таким образом, эти права имеют общее происхождение, которое возникает в омиссивном или сочувственном поведении противной стороны, которое затрагивает права, которые выходят за рамки $\mathrm{RC}: 103914$

Доступно в: https://www.nucleodoconhecimento.com.br/закон/права-солидарности 
простого индивидуального аспекта и создают коллективное притязание, вынося на обсуждение вопросы, превосходящие единственное простое заблуждение.

Согласно уроку Zavascki (2005, стр. 21), они делимы, индивидуально применимы, доступны, могут быть переданы и представлены в суде держателем, эпизодически солидарны, субъективно детерминированы и подлежат непосредственному ремонту.

Однако характеристика индивидуальности не устраняет выдающегося солидарного содержания однородных индивидуальных прав. При коллективном рассмотрении эти права выходят далеко за рамки частных интересов их владельцев. Коллективная характеристика заключается не в невозможности индивидуального присвоения или в том, что их обладатели не определены, а в масштабах, которые нарушение раскрывает для общества (ZAVASCKI, 2005, с. 21-22). Ущерб однородным индивидуальным интересам нарушает социальный мир и вызывает большой социальный дискомфорт, который создает синергетический эфффект, поскольку оба они усиливаются.

Можно было бы также назвать соответствующие индивидуальные интересы или общие интересы, что не было сделано, поскольку однородность необходима для возможности коллективной защиты закона (ZAVASCKI, 2005, стр. 19).

Также в права солидарности солидарности возникают категории диффузных и коллективных прав stricto sensu. Во-первых, дифффузными правами являются те коллективные интересы, которые неделимы, обладатели которых неопределимы и не имеют между собой правоотношений (DIDIER JUNIOR; ZANETI JUNIOR, 2014, с. 76-78). Понятие дифффузных прав обнаруживается путем анализа ст. 81, I, Кодекса защиты прав потребителей, которые концептуализируются как солидарности интересы неделимого характера, обладатели которых неопределенны и связаны общим фрактом.

Дифффузные права - это те, которые принадлежат к коллективу субъектов, которые являются неопределенными, несут неделимые права и связаны 
ситуацией фракта (последующий). То есть отношения между владельцами возникли в момент после причинения вреда, поскольку не было никакой связи между потерпевшим в предыдущее время и тем фрактом, что дало повод для коллективной защиты (DIDIER JÚNIOR; ZANETI JÚNIOR, 2014, с. 78).

Кроме того, существуют коллективные права stricto sensu, которые определены в ст. 81, II CDC. Это права солидарности с той разницей, что их владельцами являются определенные определенные группы людей, то есть между держателями существуют базовые юридические отношения, которые являются неопределенными, но поддающимися определению. Другими словами, разница между дифффузными и коллективными правами stricto sensu заключается в том, что первые имеют неопределенное право собственности, а вторые имеют определенные коллективные категории в качестве владельцев титулов, так что люди могут быть определены (DIDIER JÚNIOR; ZANETI JNIOR, 2014, p. 78-79 ).

Для коллективных интересов stricto sensu важно определить, какой группе лиц был причинен вред, поскольку право неделимо, а обладателями являются те, кто принадлежит к определенной категории (DIDIER JÚNIOR; ZANETI JÚNIOR, 2014 , c. 78).

Стоит отметить, что основные правоотношения должны быть до наступления вредного события. То есть правоотношения между держателями возникают не из ущерба, как это происходит в дифффузных правах, а из-за принадлежности к трудовой категории, ассоциации, определенному обществу и другим причинам, предшествовавшим травме (DIDIER JÚNIOR; ZANETI JÚNIOR, 2014, с. 78). Таким образом, обладатели права полностью поддаются определению и принадлежат к коллективу, который индивидуализируется.

\section{2. ЗАКОННОСТЬ}

В ситуациях исключительной юрисдикции почти всегда рассматриваемые темы представляют интерес только для сторон, участвующих в курсе, не имея 
прямого веса для лиц, которые не участвуют в пассивном или активном полюсе курса.

Традиционно активная легитимность защиты индивидуальных интересов требует изучения права собственности и восходит к наследию римского права (DIDIER JÚNIOR; ZANETI JÚNIOR, 2014, с. 79). С другой стороны, институт права от имени другого лица не является чем-то гораздо более актуальным, так как «[...] в средние века еще не существовало понятия правосубъектности, так что даже нельзя было считать, что кого-то представляет другое лицо; обычная легитимность была абсолютным правилом» (ZAVASCKI, 2005, стр. 11).

В бразильской правовой системе общая норма предусмотрена в статье 18 Гражданско-процессуального кодекса, которая ставит право собственности на право в качестве основополагающего требования для его обсуждения, поскольку обсуждение права, принадлежащего лицу другого лица, с учетом случаев, прямо предусмотренных законом, остается.

Однако, помимо обычной легитимности, изображаемой ст. 18 СРС, существует, в исключительных случаях, чрезвычайная активная легитимность, которая признается в случаях, прямо предусмотренных законом, в которых кто-то будет отстаивать право от имени держателя. В этом случае существует законодательный вариант по делам, где можно будет ссылаться на право других лиц в суде.

Помимо случаев, предусмотренных юридическим лицом, гипотезы чрезвычайной легитимности должны рассматриваться как логическое следствие правовой системы. Neves (2016) является одним из авторов, которые комментируют возможность чрезвычайной легитимности при отсутствии явного юридического разрешения:

Apesar de o art. 18, caput, do Novo CPC prever que a legitimação depende de autorização expressa da lei, a melhor doutrina entende que, além da previsão legal, também se admite a legitimação extraordinária quando decorrer logicamente do sistema, como acontece com a legitimação recursal do advogado em apelar do

$\mathrm{RC}: 103914$

Доступно в: https://www.nucleodoconhecimento.com.br/закон/права-солидарности 
capítulo da sentença que versa sobre seus honorários advocatícios (NEVES, 2016, p. 188).

Гибкость по отношению к норме ст. 18 СРС выступает как лучшая фрорма эфффективности института, призванного отстаивать интересы коллектива. Однако предупреждается: фрлексибилизация не приносит как неизбежное последующее наблюдение более простую процедуру.

Заметно, что одно и то же право может быть гарантировано людям из разных социальных групп, что происходит с некоторой частотой, например, при нарушении социальных гарантий. Поэтому трудно утверждать, что существует законность представлять всех заинтересованных лиц, учитывая большие культурные, социальные или экономические различия, которые существуют между правообладателями в коллективных требованиях.

Именно в этом контексте (ZAVASCKI, 2005, стр. 15) начались трудности защиты коллективных интересов. Если люди разные, как вы предполагаете, что один из них имеет законность требовать от всех в защиту этого общего интереса? Как можно распространить последствия коллективной защиты на тех, кто не предстает перед судом, если нельзя предположить, в чем заключается законный интерес этих других? Как вы требуете, чтобы большие группы появлялись в суде? Как это сделать, если члены группы даже не определены?

Ввиду неопределенности держателей, большой разницы, существующей между ними, и практической трудности всех выносить определенные вопросы в суд, легитимация субъектов, имеющих своей целью поиск и защиту интересов коллектива.

Таким образом, узаконенные коллективы не являются обладателями прав, которые узаконены, чтобы ссылаться, и обладатели этих прав имеют активную собственность опустошенной (NEVES, 2016, стр. 189). В письме Zavascki (2005, стр. 15) активная легитимность коллективных требований может быть названа репрезентацией отсутствующих.

$\mathrm{RC}: 103914$

Доступно в: https://www.nucleodoconhecimento.com.br/закон/права-солидарности 
В коллективной юрисдикции нет прямой связи между правом собственности на право и легитимностью, но существует правовая ситуация, которая приносит способность определенных институтов защищать интересы, которые не ограничиваются идеей индивидуализма, что приводит к конфиггурации чрезвычайной легитимности. В этом смысле:

A legitimação ao processo coletivo é extraordinária: autoriza-se um ente a defender, em juízo, situação jurídica de que é titular um grupo ou uma coletividade. Não há coincidência entre o legitimado e o titular da situação jurídica discutida (DIDIER JUNIOR; ZANETI JUNIOR, 2014, p. 21).

Бразильская правовая система согласилась с возможностью узаконить способность некоторых институтов защищать коллективные требования (ZAVASCKI, 2005, стр. 102). То есть те, которые узаконены для целей коллективных исков, вытекают из правового установления, как это имеет место в статье 5 Закона о публичных гражданских исках, в которой прокуратура, управление государственного защитника, Федеральный союз, штаты, федеральный округ, муниципалитеты и другие субъекты перечислены в качестве представителей коллектива и способных подавать публичные гражданские иски.

B рамках того же движения LACP статья 82 Кодекса защиты прав потребителей подчеркивает активную легитимность прокуратуры, Союза, штатов и муниципалитетов, муниципалитетов, публичных компаний, фрондов, обществ или ассоциаций со смешанной экономикой в деле защиты диффузных, коллективных или индивидуальных однородных прав потребителей.

Кроме того, в связи с активной легитимностью для целей коллективных действий Zavascki (2005, стр. 132) поднимает спорный аспект, который окружает возможность того, что прокуратура будет защищать однородные индивидуальные интересы, поскольку CRFB/88 не наделяет parquet эту функцию.

RC: 103914

Доступно в: https://www.nucleodoconhecimento.com.br/закон/права-солидарности 
В пункте III статьи 129 конституции защита однородных индивидуальных интересов не упоминается в качестве одной из компетенций прокуратуры, деятельность которой связана с текстом Конституции. Таким образом, можно трактовать как правовое ограждение отсутствие решимости отстаивать эти интересы (ZAVASCKI, 2005, с. 132).

Другие выступают за неограниченную легитимность прокуратуры (ZAVASCKI, 2005, стр. 133). В зависимости от пункта IX статьи 129 CRFB/88 в фуункции МП входит выполнение функций, совместимых с его целью, которая включает защиту социальных и индивидуальных интересов, недоступных в свете статьи 127 CRFB/88. Для этого течения солидарности интересы имеют презумпцию социальной значимости, что позволяет parquet действовать (ZAVASCKI, 2005, стр. 133).

Наконец, существует тезис об ограниченной легитимности, который возникает как следствие идеи о том, что государственный обвинитель будет иметь неограниченную легитимность, с предупреждением о том, что вопросами, имеющими социальную значимость, могут быть только те, которые содержат соответствие с конституционными функциями parquet (ZAVASCKI, 2005, стр. 132), это основано на статье $127, \mathrm{CRFB} / 88$, без попыток презюмировать значимость для того, чтобы иметь возможность придать легитимность государственному прокурору.

О легитимности прокуратуры в защите однородных индивидуальных интересов Zavascki приходит к выводу, что ответ на этот вопрос лежит через анализ юридических костюмов, поскольку именно в законе заложено понятие интереса социальной значимости, которое обеспечит активную легитимность parquet (ZAVASCKI, 2005, стр. 132). Таким образом, Zavascki учит, что интересы социальной значимости состоят из: «навязывания недоступности, прямого присвоения легитимности прокуратуре для ее защиты и выраженной характеристики социальной значимости» (ZAVASCKI, 2005, стр. 136).

RC: 103914

Доступно в: https://www.nucleodoconhecimento.com.br/закон/права-солидарности 
Делинда бесспорна. В отсутствие аспекта социальной значимости, изображенного Zavascki, нет необходимости говорить о легитимности parquet, чтобы действовать в защиту однородных индивидуальных интересов.

Наконец, стоит выделить характеристики, которые Didier раскрывает в активной коллективной легитимации, как норма статьи 5 Федерального закона № 7,347/85 и ст. 82 CDC, будучи перевозимой субъектами, которые не действуют от своего имени, поскольку держатели не обладают постулаторной дееспособностью:

Enfim, o certo é que a legitimação coletiva possui as seguintes características: a) está regulada, inicialmente, por lei (art. 5ำ da Lei Federal no 7.347/85; art. 82 do CDC etc.); b) é conferida a entes públicos, privados e despersonalizados, e, até, ao cidadão, na ação popular; c) o legitimado coletivo atua em nome próprio na defesa de direitos que pertencem a um agrupamento humano (pessoas indeterminadas, comunidade, coletividade ou g rupo de pessoas, titulares de direitos individuais abstratamente considerados, na forma do a1i. 81 do CDC e seus incisos); d) esse agrupamento humano não tem personalidade judiciária, portanto não pode atuar em juízo para proteger os seus direitos, 26 cuja defesa cabe aos legitimados coletivos, que possuem legitimação autônoma, exclusiva e concorrente e simples (DIDIER JUNIOR; ZANETI JUNIOR, 2014, p. 212).

\section{3. КОМПЕТЕНЦИЯ}

Компетентность является основополагающим элементом для удовлетворения надлежащей правовой процедуры. Защита прав солидарности происходит в пользу коллектива, который может быть разделен и без какой-либо связи, которая его объединяет, что обращает внимание на момент фриксации компетенции.

Для фриксации территориальной компетенции в коллективных требованиях Невес перечисляет семь шагов, необходимых для раскрытия компетентного суждения. Подчеркивается, что фриксация территориальной юрисдикции является следствием анализа процессуального законодательства, как это делается в случаях единичной защиты, поскольку это вопрос, связанный с 
правом, трактуемым изономическим образом индивидуальной защитой (NEVES, 2016, стр. 168).

Вместе с тем необходимо подчеркнуть, что законодательство, регулирующее защиту коллективных прав, может устанавливать юрисдикцию, исходящую из определенных судов или нетипичных органов, в порядке того, что может произойти в рамках специального коллективного процесса, народного иска, публичного гражданского иска, коллективного судебного запрета, коллективного ордера и действия административного проступка.

В связи с актуальностью мер стоит отметить, что компетенция в коллективной сфрере регулируется искусством. 2, Закон о публичных гражданских исках и 93 Кодекса о защите прав потребителей, которые устанавливают в качестве критерия территориальной подсудности место ущерба.

Кроме того, в зависимости от законодательства LACP компетенция будет территориальной и функциональной, что вызывает дискуссию о том, будет ли компетенция обусловлена фрорумом, территориальным вопросом или большей эфффективностью и легкостью в силу функционального критерия. Тем не менее, несомненно, что территориальная юрисдикция является абсолютной, что приводит к ее обязательному соблюдению.

После определения компетентного суда начинается поиск компетентного решения, что будет сделано из законов об организации судебной власти и СРС. Это связано с тем, что юрисдикция судебного решения зависит от территориальной юрисдикции, а не наоборот (NEVES, 2016, стр. 186).

\section{4. ИСПОЛНЕНИЕ СУДЕБНОГО РЕШЕНИЯ, ВЫНЕСЕННОГО ПО ГРУППОВЫМ ИСКАМ}

Основанием для исполнения индивидуального судебного решения является исполнение коллективного судебного решения, которое должно иметь место как продолжение процесса ознакомления, после момента, когда должник не 
выполнил предписание приговора. Этап реализации будет выполнен путем выполнения судебного решения в соответствии с обстоятельствами, предусмотренными ст. 515 СРС.

В отношении дифффузных и коллективных прав stricto sensu защита материального права будет осуществляться посредством коллективного исполнения, которое будет разворачиваться на благо общества, что будет осуществляться через аспекты, используемые в индивидуальном исполнении, без какой-либо процессуальной специальности из-за коллективного характера интереса (NEVES, 2016, стр. 392-393).

Из исполнения может возникнуть судебный запрет (запрет на незаконность) или репарационный in natura, как возмещение убытков, или наличными, которые в этом случае должны быть возвращены юридическому лицу публичного права, которому был причинен вред, или Фонду диффууных прав (статья 13 Федерального закона No 7.347/1985) (DIDIER JÚNIOR; ZANETI JÚNIOR, 2014, c. 412).

Что касается легитимности, то любая неотъемлемая часть активного полюса может способствовать исполнению, даже если она не участвовала в фазе познания, в соответствии с толкованием статьи 15 Закона 7.347, в которой в качестве требования указана 60-дневная задержка окончательного транзита, чтобы новые субъекты могли участвовать в процессе с целью инициирования этапа реализации (DIDIER JÚNIOR; ZANETI JÚNIOR, 2014, с. 413). То есть коллективное исполнение дифффузных или коллективных прав stricto sensu может быть осуществлено любым внеочередным узаконенным, соблюдающим временной ход конечного транзита. Это также предусмотрено в ст. 15 CВРСIBDP и ст. 26 CBPC-UERJ/UNESA.

Подчеркивается обязанность предлагать исполнение судебного решения как существенную атрибуцию parquet, заботясь о коллективных интересах (NEVES, 2016, стр. 391). 
Вместе с тем следует отметить, что обязанность государственного прокурора исполнить судебное решение по публичному гражданскому иску возникает по истечении 60 дней после вынесения окончательного приговора в соответствии со статьей 15 Закона 7.347/85.

Что касается народного иска, то обязанность прокуратуры привести приговор в исполнение не выполнена, если гражданин инертен в течение более 60 дней, что отсчитывается от опубликования решения второй степени в соответствии со статьей 16 Закона 4.717/65. То есть, функциональная обязанность движущегося parquet будет соответствовать предварительному предложению до возможности изменения команды предложения.

Таким образом, существует также возможность индивидуального правоприменения при исполнении диффрузных и коллективных прав stricto sensu,согласно уроку Didier:

É também possível que a sentença proferida em um processo em que se discutem direitos difusos ou coletivos seja utilizada por um indivíduo corno título de uma execução individual, tendo em vista a extensão in utilibus da coisa julgada coletiva ao plano individual, já examinada. Obviamente, antes de executar a decisão, o indivíduo deverá proceder à liquidação do seu crédito, em que deverá demonstrar, inclusive, que é titular de um crédito (liquidação com thema decidendum mais amplo do que a liquidação individual prevista no CPC, restrita à decisão sobre o valor ou sobre a coisa a ser executada) (DIDIER JUNIOR; ZANETI JUNIOR, 2014, p. 415).

Что касается однородных индивидуальных прав, которые представляют собой индивидуальные права, агрегированные по их общему происхождению, то их реализация будет осуществляться индивидуально обладателями. То есть сильный компонент коллективности, который существовал в фразе знаний, замедлился на этапе исполнения, поскольку индивидуальный интерес будет рассматриваться как коллективный на этапе исполнения (NEVES, 2016, стр. 394). Что касается а, то статья 516 СРС устанавливает строгую норму, критерий абсолютной юрисдикции, который привел бы к соблюдению решения по делу, которое решало дело в первой степени юрисдикции.

RC: 103914

Доступно в: https://www.nucleodoconhecimento.com.br/закон/права-солидарности 
Толкование этого правового положения включает в себя индивидуальное исполнение коллективного судебного решения, однако по критериям практичности Neves (2016, стр. 376) защищает как компетентный для индивидуального урегулирования коллективного суждения суд по месту жительства ликвидатора, так что нет большой концентрации разбирательства в округе, который принял решение по делу в первой степени юрисдикции, и меньше бремени для исполнительного директора.

Однако следует отметить, что в отношении единственного пункта ст. 97 CDC имело место президентское вето, которое исключает гипотезу о том, что форум исполнения коллективного решения выбирается как место жительства экзекента.

По мнению Zavascki (2005, с. 164), нет никакой возможности считать вето бесполезным, поскольку оно открывает путь к толкованию и выявляет причины, которые должны быть рассмотрены, поскольку рассматриваются законодателями.

Ввиду прямого определения юрисдикции для исполнения судебного решения, именно в судебном решении, рассматривающем дело в первой степени подсудности, согласно ст. 516 II СРС сомнений в подсудности не существует.

Наконец, в ст. 98 CDC есть спорный момент, касающийся возможности прокуратуры и государственных органов (узаконенных ст. 82 CDC) содействовать исполнению однородных индивидуальных интересов, поскольку коллективная сфрера пуста в момент исполнения индивидуальных интересов. Подчеркивая урок Zavascki:

Quanto ao Ministério Público e órgãos públicos, não se vislumbra circunstância na qual tais entes teriam algum interesse em promover liquidação e execução específicas em favor de particulares, ainda mais mediante representação. Em consequência, é certo não possuir - Ministério Público legitimidade para promover o tratamento individualizado da sentença genérica, mas não porque ele não tem poderes para agir em nome próprio em favor das vítimas e sucessores e sim porque, nessa hipótese, não se trata de defesa de

RC: 103914

Доступно в: https://www.nucleodoconhecimento.com.br/закон/права-солидарности 
interesses sociais ou individuais indisponíveis (ZAVASCKI, 2005, p. 163).

Наконец, интересно отметить, что даже те, кто не является частью процесса, могут жаловаться на то, что было предложено в коллективном решении, поскольку его цель состоит в том, чтобы придать конкретность правам сообщества:

Diante disso, os instrumentos processuais utilizados para tutela dos interesses transindividuais devem ser adaptados à natureza do interesse substancial em questão, de modo a lhe proporcionar uma maior efetividade. Para tanto, algumas alterações legislativas foram feitas com a finalidade de atender esse escopo. Dentre elas menciona-se a tratativa dada à sentença coletiva, à coisa julgada e à execução de sentença coletiva. A sentença coletiva, dada sua natureza, possui um alcance diferenciado no que se refere aos indivíduos por ela albergados, podendo atingir, inclusive, aquele que não foi parte no processo, dada a extensão secundum eventum litis da coisa julgada coletiva ao plano individual (ALFREDO, BALEOTI, 2012, p. 435).

\section{5. ХРАНИТЕЛИ СРОЧНОСТИ КОЛЛЕКТИВНЫХ ДЕЙСТВИЙ}

В целом, защита срочности в коллективных действиях не представляет собой расхождения в рассуждениях по отношению к индивидуальным действиям (DIDIER JÚNIOR; ZANETI JÚNIOR, 2014, p. 342), который приводит к возникновению СРС при наличии требований, изложенных в его ст. 300.

Однако существуют определенные специальные процедуры, которые предусматривают этот процессуальный метод, такие как статья 12 LACP, которая позволяет предоставлять раннюю защиту при защите определенных коллективных интересов (DIDIER JÚNIOR; ZANETI JÚNIOR, 2014, с. 342).

B качестве примера также ст. 4 LACP предусматривает возможность принятия обеспечительных мер в объеме предотвращения ущерба правовым активам, описанным в нем. Didier справедливо приводит к исправлению положений этой статьи, поскольку эта мера была бы удовлетворительной, поскольку она предоставила бы право, искомое в результате провокации судебной власти, а не меру предосторожности:

$\mathrm{RC}: 103914$

Доступно в: https://www.nucleodoconhecimento.com.br/закон/права-солидарности 
Embora mencione expressamente a tutela cautelar, a redação do dispositivo não dá margem a dúvida: não se trata de tutela cautelar, mas, sim, tutela inibitória, que é satisfativa e visa exatamente obter providência judicial que impeça a prática de ato ilícito e, por consequência, a ocorrência de um dano (DIDIER JÚNIOR; ZANETI JÚNIOR, 2014, p. 343).

Важно выделить определенные препятствия для предоставления временной защиты в групповых исках, такие как положения статьи 2 Федерального закона No 8,437/1992 и § 2 ст. 22 Закона No 12.016/2009, которые ограничивают вынесение судебного запрета в ордере на коллективную безопасность или публичном гражданском иске слушанием судебного представителя юридического лица публичного права, должны быть выполнены в течение максимум 72 часов.

То же самое происходит и с вынесением судебного запрета в коллективном судебном разбирательстве о владении имуществом, которое обусловлено выполнением требований, изложенных в ст. 565 Гражданского процессуального кодекса.

\section{6. КОРРЕКЦИЯ В КОЛЛЕКТИВНЫХ ДЕЙСТВИЯХ}

Нет никаких конкретных средств обжалования для использования в коллективных исках. Что есть исключительные упоминания о возможности обжалования в заявлении в коллективных требованиях, что приводит к общему применению системы обжалования Гражданского процессуального кодекса (NEVES, 2016, p. 324)

Что касается оспаривания промежуточного решения, то в ст. 1015 СРС перечислен перечень гипотез, открывающих сферу применения орудийного вреда. В зависимости от явно выраженного разрешения этой статьи, в ее пункте XIII другие случаи, предусмотренные законом, допускают управление орудийным ущербом, в котором статья 19, пункт 1, Закона 4.717/65, с положением, что целесообразно усугубить инструмент из-за решения о взаимодействии в контексте народного иска.

$\mathrm{RC}: 103914$

Доступно в: https://www.nucleodoconhecimento.com.br/закон/права-солидарности 
Согласно Neves (NEVES, 2016, р. 325), из-за коллективной микросистемы вышеупомянутая норма должна применяться во всех других коллективных действиях, что позволило бы вмешаться в нанесение ущерба инструменту в любое промежуточное решение, возникшее в коллективном процессе.

Что касается рекурсивной легитимности, то интересно проанализировать, что существуют исключения из правила 996 СРС, которое устанавливает неудачную сторону, заинтересованные третьи стороны и прокуроров в качестве законных активов для апелляций.

Следует подчеркнуть, что статья 996 СРС имеет дело с рекурсивным интересом, а не с рекурсальной легитимностью, поскольку при работе с неудачливой стороной проводится анализ уступок, что приводит к конкретному анализу решения, ставящего под сомнение обжаловать интерес (NEVES, 2016, стр. 330). Легитимность не имеет ничего общего с интересом, потому что законно прибегнуть к тому, кто выигрывает или проигрывает, критерий установления легитимности полностью независим от содержания решения.

Стоит подчеркнуть важную тему: в соответствии с правилом пункта 2 статьи 19 Закона 4.717/65, любой гражданин может обжаловать приговоры и решения, вынесенные после народного иска. Получается, что, в зависимости от нормы, заложенной в статье 996 СРС, гражданин, не составляющий активный полюс курса, не подходит в качестве неудачливой стороны или третьего лица, поскольку право в комментарии в народном действии является диффузным, что снимает понятие третьего лица, заинтересованного в единственном пункте ст. 996, СРС. Таким образом, гражданин не составляет список субъектов, обладающих рекурсивной легитимностью, а находит разрешение в LAP на обжалование.

Что касается рекурсивных эффректов (навязчивых, трансформаторных, экспансивных, замещающих, регрессивных и отложенных), то здесь нет никакой специфики, когда они порождаются в коллективном процессе. Только в отношении приостанавливающего действия необходимо проанализировать 
законодательство, относящееся к каждому действию, чтобы проверить отсутствие или наличие каждого упомянутого эффекта обжалования (NEVES, 2016, стр. 332).

Следует особо отметить законодательство, регулирующее публичный гражданский иск, которое предоставляет судье приостанавливающее действие на апелляции с объемом устранения непоправимого ущерба сторонам, в зависимости от статьи 14 Закона 7.347/1985, которая сформировала понимание того, что апелляции, поданные в рамках публичного гражданского иска, не имеют приостанавливающего действия только из-за их простого вмешательства (NEVES, 2016, с. 332). Таким образом, апелляция, которая, как правило, имеет приостанавливающие последствия, в силу статьи 1012 Гражданского процессуального кодекса, должна соответствовать требованиям, перечисленным в статье 14 LACP (избегая непоправимого ущерба в сторону), чтобы предотвратить вынесение решения по публичному гражданскому иску от немедленных последствий.

\section{7. ОКОНЧАТЕЛЬНЫЕ СООБРАЖЕНИЯ}

С учетом обсуждения, проведенного в ходе этой работы, можно отметить, что текст CRFB/88 приобретает силу и эффеективность с защитой коллективных прав, в виде поиска материализации социальных гарантий, которые предусмотрены в конституционном языке и могут быть востребованы в судебном порядке.

Такой инструмент чрезвычайно интересен для осуществления социальной справедливости в массовом обществе, где нарушение права может выйти за рамки индивидуальной сферы и достичь общности людей. С учетом этой причины в целях решения первоначально возникшей проблемы была подчеркнута конституционная предвзятость в отношении гарантирования права солидарности путем придания уникальности правовым положениям, которые направлены на обеспечение коллективных прав в сочетании с достижением принципа социальной справедливости и надлежащей правовой процедуры.

$\mathrm{RC}: 103914$

Доступно в: https://www.nucleodoconhecimento.com.br/закон/права-солидарности 
На основе изучения основных элементов коллективной защиты была представлена гармоническая система, которая находит согласованность для обеспечения защиты правового блага всей коллектива. Таким образом, проблема герметичности этой процессуальной системы была преодолена, так как к ней подходили таким образом, чтобы обсудить ее конституционную матрицу $и$ ее правовые основы. Поэтому то, что может напоминать разрозненную систему, поскольку имеет стандартизацию в различных законодательных актах, трактуется как комплексный инструмент, который движется к обеспечению прав, принадлежащих не только одному человеку, но и обществу.

\section{ИСПОЛЬЗОВАННАЯ ЛИТЕРАТУРА}

ALFREDO, Luciana Romaneli Rodrigues e BALEOTTI, Francisco Emílio. A sentença coletiva e a efetividade dos direitos transindividuais. Revista Jurídica Cesumar, Vol. 12, No 2, 2012.

BELLINETTI, Luiz Fernando; SOUZA, Raíssa Fabris. Obstáculos para a efetividade da tutela de direitos transindividuais por entidades sindicais em prejuízo ao efetivo acesso à justiça. Revista Cidadania e Acesso à Justiça, Florianópolis, SC, v. 5, p. 1-17, 2019.

DIDIER JUNIOR, Fredie; ZANETI JUNIOR, Hermes. Curso de Direito Processual Civil: processo coletivo. 9. ed. Salvador: JusPodivm, 2014.

HACHEM, Daniel Wunder. A dupla titularidade (individual e transindividual) dos direitos fundamentais e econômicos, sociais, culturais e ambientais. Revista de Direitos Fundamentais e Democracia, v. 14, n. 14, Curitiba, p. 618-688, jul./dez. 2013.

NEVES, Daniel Amorim Assumpção. Manual de processo coletivo. São Paulo: Método, 2016. 
SANTOS, Enoque Ribeiro dos. Processo coletivo do trabalho. 2. ed., rev., atual. e ampl. Rio de Janeiro: Forense, 2018.

ZAVASCKI, Teori Albino. Processo coletivo: tutela de direitos coletivos e tutela coletiva de direitos. Tese (Doutorado Programa de Pós-graduação em Direito) Faculdade de Direito da Universidade Federal do Rio Grande do Sul, Porto Alegre, 2005.

Представлено: Декабрь 2021 года.

Утвержден: Декабрь 2021 года. 